\section{Biologists bugged by space station cuts and uncertainties}

Tony Reichhardt, Washington

The US space agency NASA last week

tried to reassure scientists that it intends

to furnish the International Space

Station with its planned complement of research equipment. But some hardware will arrive years later than planned. And neither NASA nor the White House can yet say how the agency will pay for any science facilities installed after 2003.

Mark Uhran, director of research integration for the NASA office sponsoring station research, told a task force of the National Academy of Sciences that it was not a question of whether the facilities would be built, "it's a question of when".

His remarks were meant to allay space biologists' fears that some vital hardware - including a centrifuge for investigating the effects of gravity on test animals and plants - might be scrapped (see Nature 410, 399; 2001) because of a projected $\$ 4$ billion shortfall in the station's budget for the next five years.

The planned US contribution is 27 'racks' of research hardware - multipurpose facilities each about the size of a fridge-freezer. The first 10 are nearly complete, said Uhran, and will launch by the end of next year. Partners will contribute their own lab equipment.

When the remaining racks, including facilities for life sciences, fluids and combustion research and materials science, will be installed is less certain. The latest schedule suggests 2004 to 2006. But Uhran said he could only give a date once NASA had restructured the station's budget in a few months' time.

NASA administrator Dan Goldin told the House Science Committee last week that one option for proceeding after 2004 would be to have European or Japanese partners pay for some lab equipment perhaps in exchange for more use of the station (the United States has 75\% use).

France and Italy are interested in building the crew rescue vehicle and living quarters, both recently cancelled by NASA to save money. Without the rescue vehicle, the station would be limited to three crew members.

Meanwhile, one partner has its own troubles. Japan's space agency NASDA is building the centrifuge for NASA in exchange for a ride on the US space shuttle for Japan's laboratory module. But NASDA managers admit hardware development problems will delay the centrifuge to 2008 at the earliest.

\section{Report fudges issue as South Africa fights on against HIV}

Michael Cherry, Cape Town

South Africa is set to continue with health policies acknowledging that HIV causes AIDS, after the final report of a government-sponsored panel fudged the question of whether the causal link is proven.

The controversial panel, established last year by President Thabo Mbeki and including many 'dissidents' who dispute the link, produced a report containing several contradictory recommendations, designed to accommodate both sides of the argument.

The report recommends, for example, that testing for HIV infection be suspended "until its relevance is proved especially in an African context, given the evidence of false positive results in an African setting". But it also calls for continued "surveillance of HIV prevalence in antenatal clinics, blood banks and among workers".

Although offering no resolution on the issue, several observers say the report will enable President Mbeki to save face, while allowing the health department to proceed with AIDS policies that acknowledge that HIV causes AIDS.

The panel met twice last summer to consider the causes of the disease. But after its report was released last week, Manto Tshabalala-Msimang, the health minister, conceded that the panel had failed to reach a consensus. She said the government would continue with its existing AIDS programme, while supporting research suggested by the panel into the causes of AIDS (see box).

The director-general in the health department, Ayanda Ntsaluba, declared publicly last October that HIV causes AIDS, and began implementing a pilot programme using antiretroviral drugs to prevent motherto-child transmission of the disease.

The dissidents appear to be at least partially satisfied by the door being left open for further research.

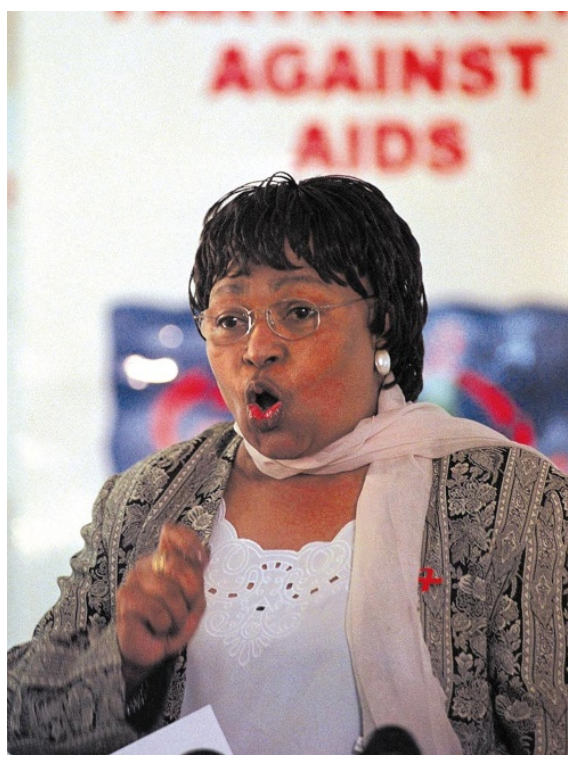

The way ahead: Tshabalala-Msimang promises that existing anti-HIV measures will continue.

The report's author, Khotso Mokhele, president of the National Research Foundation, recommended last week that another committee be established to consider the merits of these proposals. TshabalalaMsimang expressed hope that at least some financial support would be forthcoming from outside South Africa.

The long delay in the report's arrival has been the subject of speculation. Initially due at the end of last year, it was handed to Tshabalala-Msimang on 18 January, but she subsequently returned it to the panel's secretariat to deal with what she called "editorial changes of a non-scientific nature".

According to panellist Salim Karim, who is head of the HIV/AIDS unit at the Medical Research Council, "the process of compiling the report was out of the hands of the panellists".

\section{Researchers probe the link between virus and AIDS}

As part of the South African panel's investigation, a programme of experiments is under way to satisfy any doubts over whether HIV causes AIDS.

In the first of these, blood tests for HIV from five laboratories in South Africa were retested at the US Centers for Disease Control in Atlanta, Georgia. The new tests were $99.9 \%$ consistent with the originals indicating that HIV testing in South Africa is highly reliable.

A second experiment will investigate the claim made by some dissidents that these test results are disrupted by reactions with antibodies raised in response to other diseases, such as malaria and tuberculosis. This work is due to be complete within six to nine months.

A further experiment will use an approach based on the polymerase chain reaction to screen test samples simultaneously for several diseases (or strains thereof) while significantly reducing the risk of contamination. This work is expected to measure the number of multiple infections, and to help identify strains of both tuberculosis and HIV that are resistant to treatment. 